\title{
Physical properties of boundary layers in angular contact ball bearings lubricated with greases containing polymers
}

\author{
M M Gatzen ${ }^{1 *}$, F Pape ${ }^{2}$, and G W G Poll ${ }^{1}$ \\ ${ }^{1}$ Institute for Machine Elements, Engineering Design, and Tribology (IMKT), Leibniz Universitaet Hannover, Germany \\ ${ }^{2}$ Institute for Microtechnology (imt), Leibniz Universitaet Hannover, Germany
}

The manuscript was received on 2 September 2008 and was accepted after revision for publication on 6 January 2009.

DOI: 10.1243/13506501JET529

\begin{abstract}
This article describes the effect of polymer additives in lithium greases on performance and boundary layers of high-speed angular contact ball bearings. High-speed test rigs were used to run grease life tests utilizing five lithium grease variants that were derivatives from the same basic grease composition. While one was used in its plain state, the other four were blended with polymer additives. The test runs showed different operating characteristics of the greases with total service lives $\left(L_{10}\right)$ ranging from 139 to $1010 \mathrm{~h}$. Furthermore, the operating temperatures of the greases varied by up to $11^{\circ} \mathrm{C}$. After test run completion, surface hardness was measured on the raceways using a nanoindentation system with a triangular diamond pyramid Berkovich tip and an applied force of $1.5 \mathrm{mN}$. As a reference, a 'virgin' bearing was studied having not yet been in contact with grease. Thereafter, measurements were performed on samples that had been in contact with the five described greases. It is shown that polymer additives indeed can influence the properties of boundary layers, thereby affecting the bearing's service life and friction.
\end{abstract}

Keywords: tribology, bearings, grease, boundary layers, lubrication, polymers

\section{INTRODUCTION}

The main goals of tribological research related to rolling element bearings are to reduce friction and extend service life. Particularly under severe operating conditions, such as starved lubrication, as is the case in grease-lubricated high-speed bearings, further development of greases and additives is vital.

In engine oils, additives known as viscosity index improvers (VI-improvers) have been used in the past to modify the overall rheological behaviour. In most cases, polymer additives are utilized [1] .

Polymer additives can exhibit different effects when dispersed in oil. They mainly modify the temperature viscosity relation behaviour, but also may influence shear losses and the replenishment mechanism of lubricant to the raceways [2]. Furthermore, Spikes

\footnotetext{
${ }^{*}$ Corresponding author: Institute for Machine Elements, Engineering Design, and Tribology, Leibniz Universitaet Hannover, Hannover, Germany.

email:gatzen@imkt.uni-hannover.de
}

et al. showed the influence of polymer additives on the formation of boundary layers [3-5].

\subsection{The mechanisms of polymer-lubricant interaction}

At low operating temperatures lubricants with low viscosity are generally desirable in order to keep shear losses and thus friction low. However, the dramatic drop of viscosity of plain oils at higher temperatures can lead to mixed lubrication with increased friction and wear. This behaviour can be improved by adding certain polymers to the base oil.

Figure 1 shows the behaviour of polymer additives in greases. At lower temperatures, polymers used as VI-improvers tend to shape themselves as coils with relatively small diameters. As temperature increases, the size of the polymer molecules increases, thus partially compensating for the reduction in viscosity of the base oil.

Due to the described temperature dependence, the VI of oils can thus be adapted to meet the requirements of all temperature regimes. 


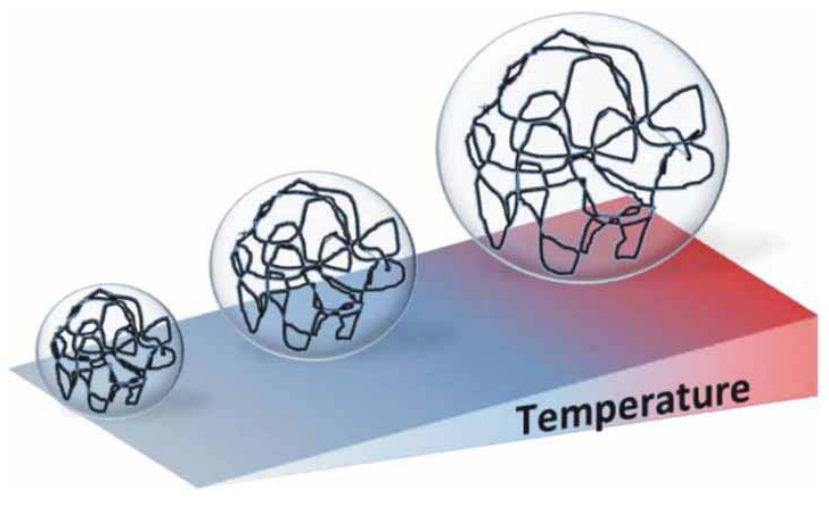

Fig. 1 Molecule size at different temperatures

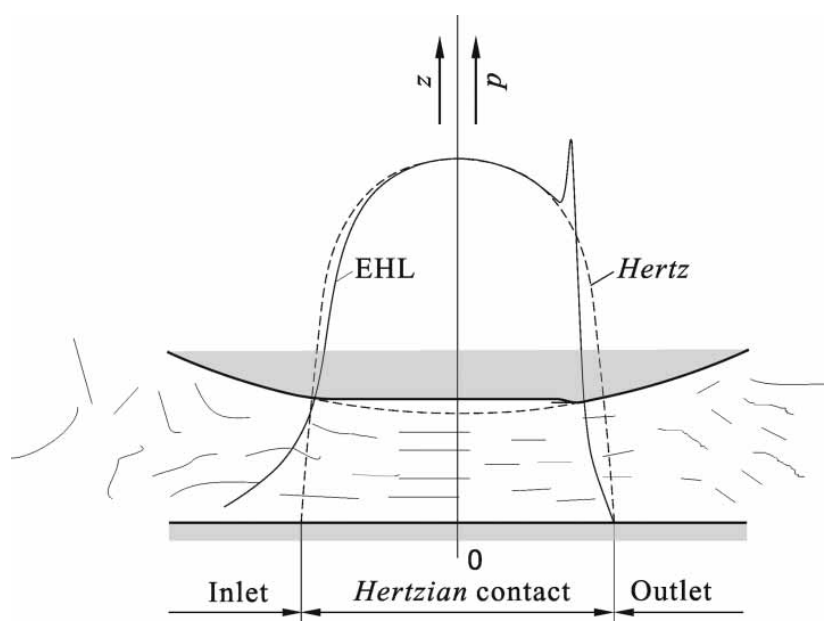

Fig. 2 Polymer molecules in a high-pressure regime

At higher operating speeds or shear rates, as is the case in the bearings studied in this article, the orientation of the polymers changes. At low shear rates, polymer molecules are randomly dispersed in the base oil. In high-pressure areas, such as a Hertzian Contact, or at high speeds the molecules align parallel to the main flow direction as is shown in Fig. 2.

In the inlet, an oil containing a VI-improver tends to have a higher viscosity than a straight base oil, which evidently leads to a greater film thickness. In the highpressure zone the polymer molecules are aligned and, also, the base oil viscosity rises sharply due to pressure; therefore, the thickening effect of the VI-improver is less distinctive. As the pressure is reduced in the outlet, the molecules are once again randomly dispersed.

The described effect is usually reversible, as long as the molecules' length is not altered. Due to high forces in the contact zone, the molecular bonds can break, leading to one long chain breaking into two shorter chains. In that case, the measured viscosity of the base oil is permanently reduced. As an overall tendency, one can state that the longer the molecular chains, the lower the limiting shear rate before the molecules will rupture [6, 7].

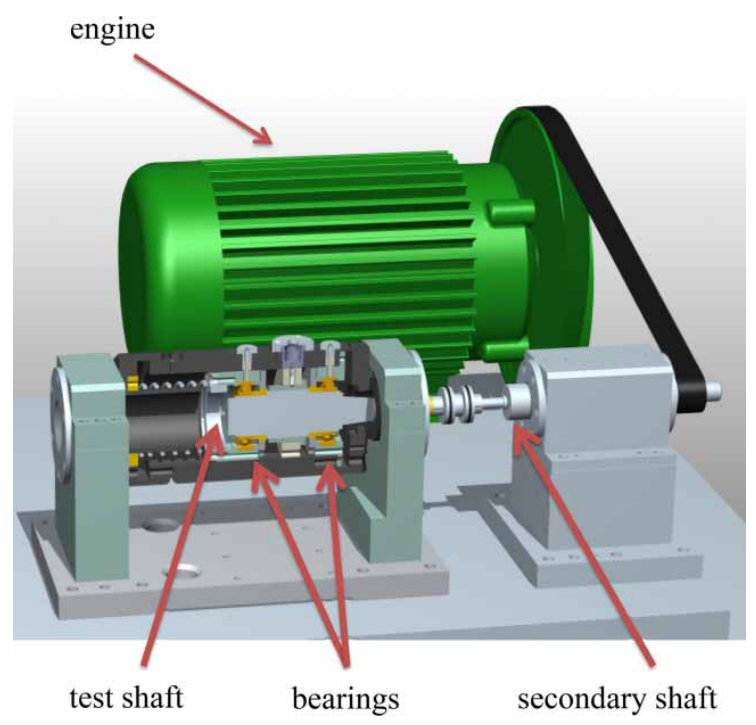

Fig. 3 High-speed test rig

While the use of polymer additives in oils has been extensively studied, the present work aims at investigating the effect of VI-improvers in lubricating greases on the operating characteristics and the boundary layers of ball bearings. Past research has shown that a better understanding of the interaction between lubricants and boundary layers can be a key to the development of improved greases $[\mathbf{8}, \mathbf{9}]$.

\section{EXPERIMENTAL SET-UP}

\subsection{Test equipment}

The grease service life tests were performed on five high-speed ball bearing test rigs, of which one is shown in Fig. 3. This specific test rig design allows a simultaneous testing of two bearing per test run, with speeds of up to $26000 \mathrm{r} / \mathrm{min}$. To monitor and evaluate the bearing, data such as temperature and rotating velocity are constantly collected.

The temperatures are measured on the test bearings' outer rings. The rotational velocity of the main shaft is determined by using a hall sensor.

Additionally to the parameters described above, the average separation of the surfaces through lubricant films or boundary layers is recorded in regular time intervals. This information is obtained by determining the electrical capacitances between shaft and housing, thus allowing the film thickness to be calculated.

\subsection{Testing parameters}

The main goal of the rig tests is to determine the greases' maximum service lives under realistic operating conditions, while simultaneously ensuring the same controlled environment for all tests. To 
Table 1 Model grease composition

\begin{tabular}{lllll}
\hline & $\begin{array}{l}\text { Thickener } \\
\text { content }\end{array}$ & $\begin{array}{l}\text { Base oil } \\
\text { content }\end{array}$ & Polymer & $\begin{array}{l}\text { Oil viscosity } \\
\text { at } 40^{\circ} \mathrm{C}\left(\mathrm{mm}^{2} / \mathrm{s}\right)\end{array}$ \\
\hline Grease I & Li-12-OH (23\%) & PAO (85\%) + Est. (15\%) & - & 17.6 \\
Grease II & & & PAMA, non dispersing, low molecular weight & 25.5 \\
Grease III & & & PAMA, dispersing, low molecular weight & 25.4 \\
Grease IV & & PAMA, non dispersing high molecular weight & 25.5 \\
Grease V & & PIB & 25.8 \\
\hline
\end{tabular}

PAO: polyalphaolefin; Est.: ester; Li-12-OH: lithium-12-hydroxystearate; PAMA: polyalkylmethacrylate; PIB: polyisobutene

achieve these goals, the following test parameters were selected.

Greases were tested using high-speed angular contact bearings type 7008 with a nominal contact angle of $15^{\circ}$ under a purely axial load of $160 \mathrm{~N}$. Before the final assembly, all bearings were cleaned to ensure that no remaining corrosion inhibitor adhering to the 'virgin' bearing influenced the testing. After this procedure, each bearing was filled with a defined amount of grease. During the first $48 \mathrm{~h}$ of the test, an automated

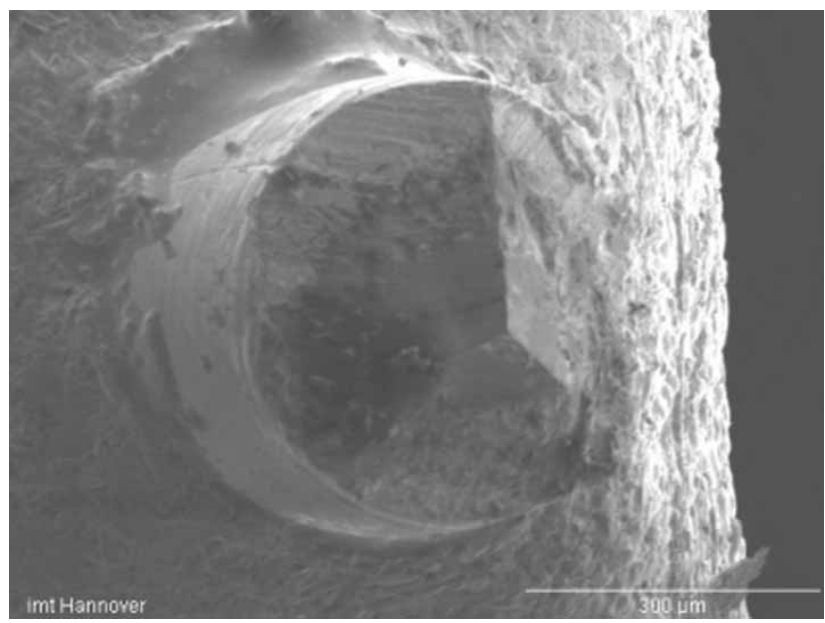

Fig. 4 SEM image of a Berkovich tip

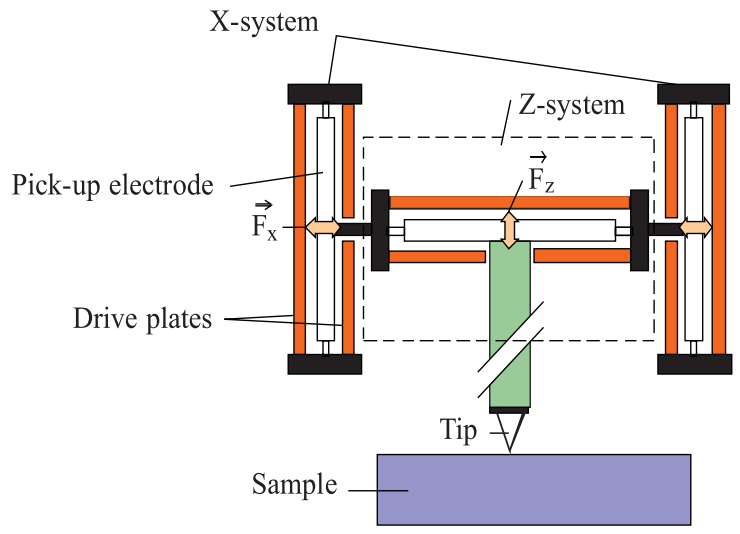

Fig. 5 Schematics of the set-up for the nanoindentation tests [10] run-in procedure was implemented. By increasing the rotating speed in defined intervals, it was ensured that the grease was equally distributed in all bearings by the time they reached the maximum rotating speed of $26000 \mathrm{r} / \mathrm{min}$ (equivalent to the characteristic speed $n \times d_{m}=1.4 \times 10^{6} \mathrm{~mm} / \mathrm{min}$ ( $n$ is the rotational speed and $d_{m}$ the mean bearing diameter)). The temperature was not controlled, but resulted from the frictional losses in the bearings.

After having reached the maximum speed, no further speed changes were made until the first

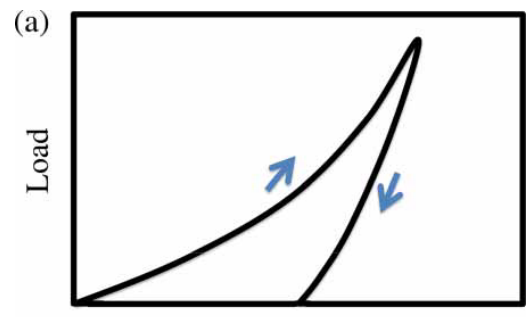

Displacement

(b)

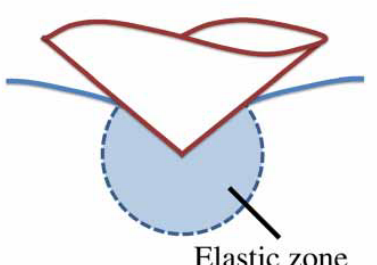

Plastic zone

Fig. 6 Elastoplastic deformation measured with nanoindentation [12]: (a) load and unload curves for elastoplastic material behaviour and (b) corresponding indent with plastic and elastic zone

Table 2 Average temperature and grease service life

\begin{tabular}{llrrr}
\hline & $T_{\mathrm{av}}\left({ }^{\circ} \mathrm{C}\right)$ & $L_{10}(\mathrm{~h})$ & $L_{50}(\mathrm{~h})$ & $\beta$ \\
\hline Grease I & 69 & 1010 & 3025 & 1.7 \\
Grease II & 73 & 380 & 1824 & 1.2 \\
Grease III & 65 & 427 & 2368 & 1.1 \\
Grease IV & 71 & 140 & 639 & 1.2 \\
Grease V & 76 & 139 & 773 & 1.1 \\
\hline
\end{tabular}

$T_{\text {av }}$ : average temperature; $\beta$ : slope; $L_{10}: 10$ per cent failure probability; $L_{50}: 50$ per cent failure probability 


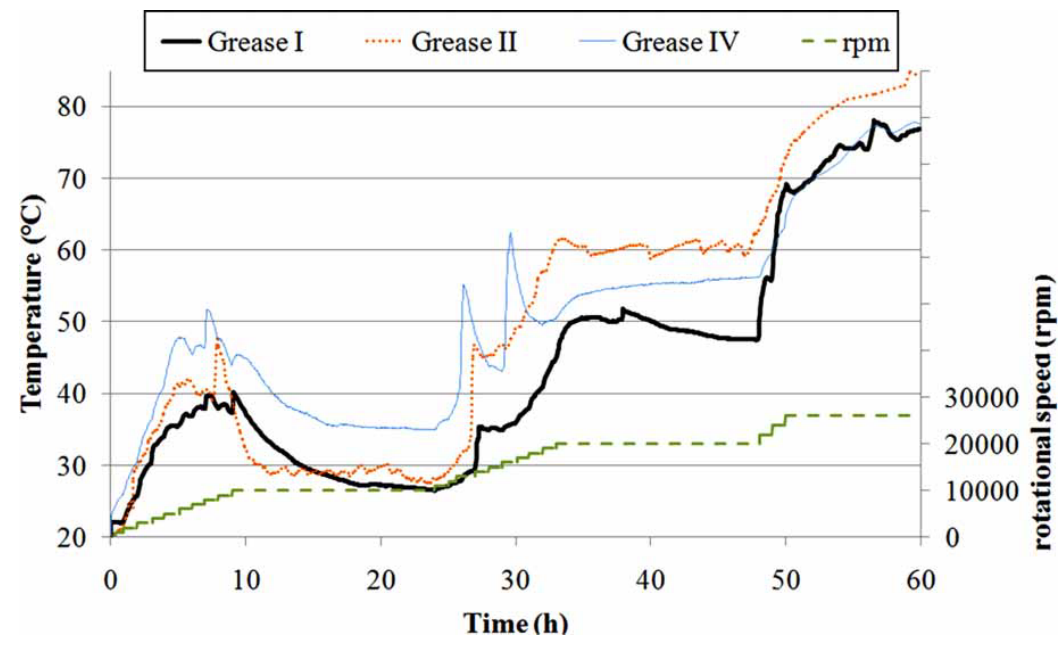

Fig. 7 Running-in period Greases I, II, and IV

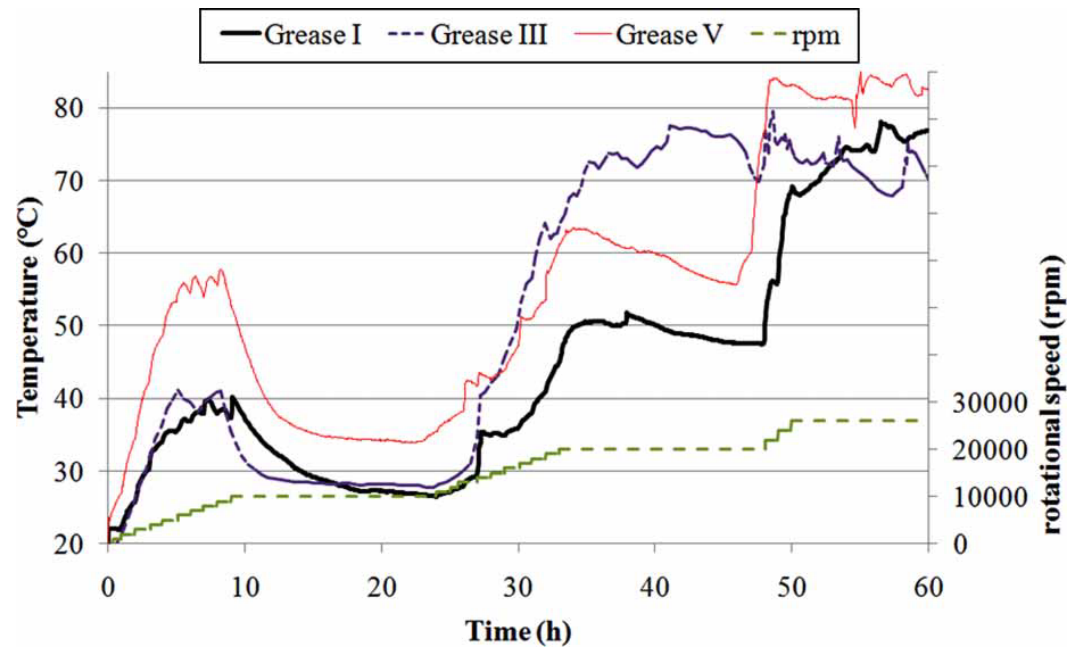

Fig. 8 Running-in period Greases I, III, and V

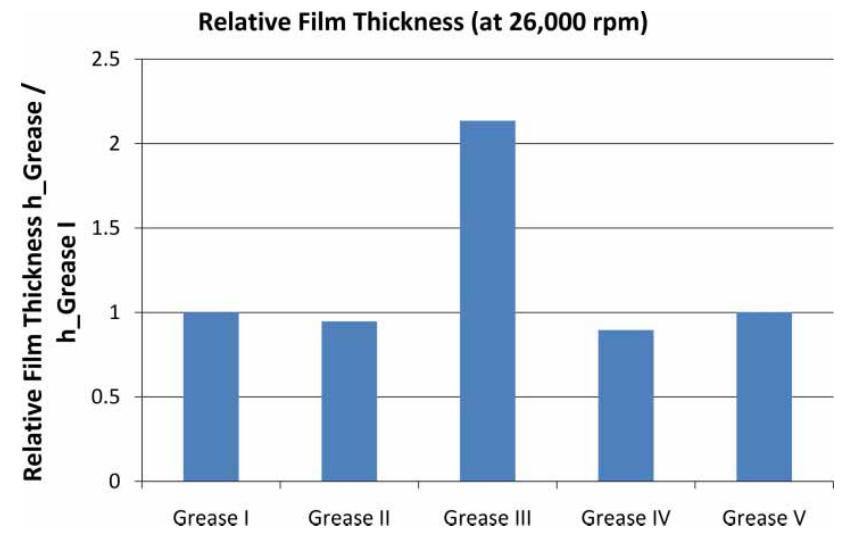

Fig. 9 Film thickness

indications of impending grease failure appeared, especially rising temperatures. In this experiment, a test run was terminated when for either one of the two bearings the measured temperature exceeded $100^{\circ} \mathrm{C}$.
According to the 'sudden death' method that bearing was declared 'failed' and the other bearing was regarded as suspended when determining the Weibull distribution of running time until failure. 


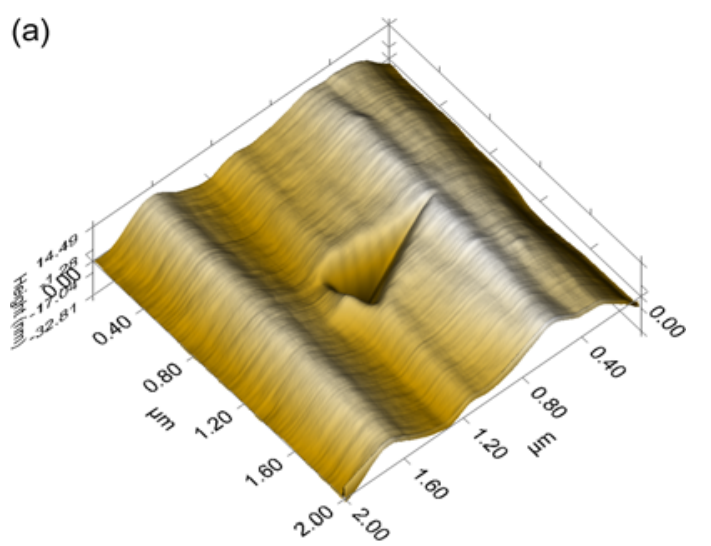

(b)

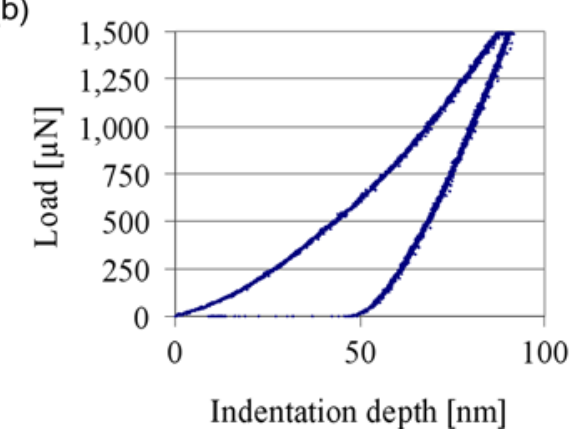

Fig. 11 (a) AFM image of an indent on the reference bearing and (b) corresponding load displacement curve of the indentation

\subsection{Model greases}

To determine the effect of polymer additives on the service life and tribological behaviour of the bearings, five similar model greases were studied. As base oil, a PAO-ester mixture was used with a composition of 85 per cent PAO and 15 per cent ester. Furthermore, lithium-12-hydroxystearate was chosen as thickener. Previous testing showed excellent operating characteristics under the described regime for greases with a relatively high percentage of thickener [8]. Therefore, a thickener content of approximately 23 per cent was applied. In addition to one grease that was used plain, four other greases were blended with polymer additives. Three of the additives were different types of polyalkylmethacrylate, and one polymer was a polyisobutene (Table 1). The amount of polymer added was chosen such that the resulting nominal viscosities of all greases with polymers was about the same and about 45 per cent higher than that for the base oil.

\subsection{Set-up for the nanoindentation studies}

One of the methods applied to characterize the mechanical properties of the bearing raceways' boundary layers were nanoindents with a Hysitron TriboIndenter ${ }^{\mathrm{TM}}$. A Berkovich tip (Fig. 4) with a triangular diamond pyramid shape allowed to measure the hardness of samples. The tip is mounted to the systems' three-plate capacitive transducer, pushing the tip by electrostatic force into the sample (Fig. 5 [10]). By changing the capacitance between the plates the resulting loading and unloading curves can be recorded.

The hardness was calculated by applying the method of Oliver and Pharr [11]. For the indentation tests that are presented here, a maximum force of $1.5 \mathrm{mN}$ was applied. During the indentation tests, the tip may deform the substrate in an elastic, plastic, or elastoplastic way as presented in Fig. 6 [12].

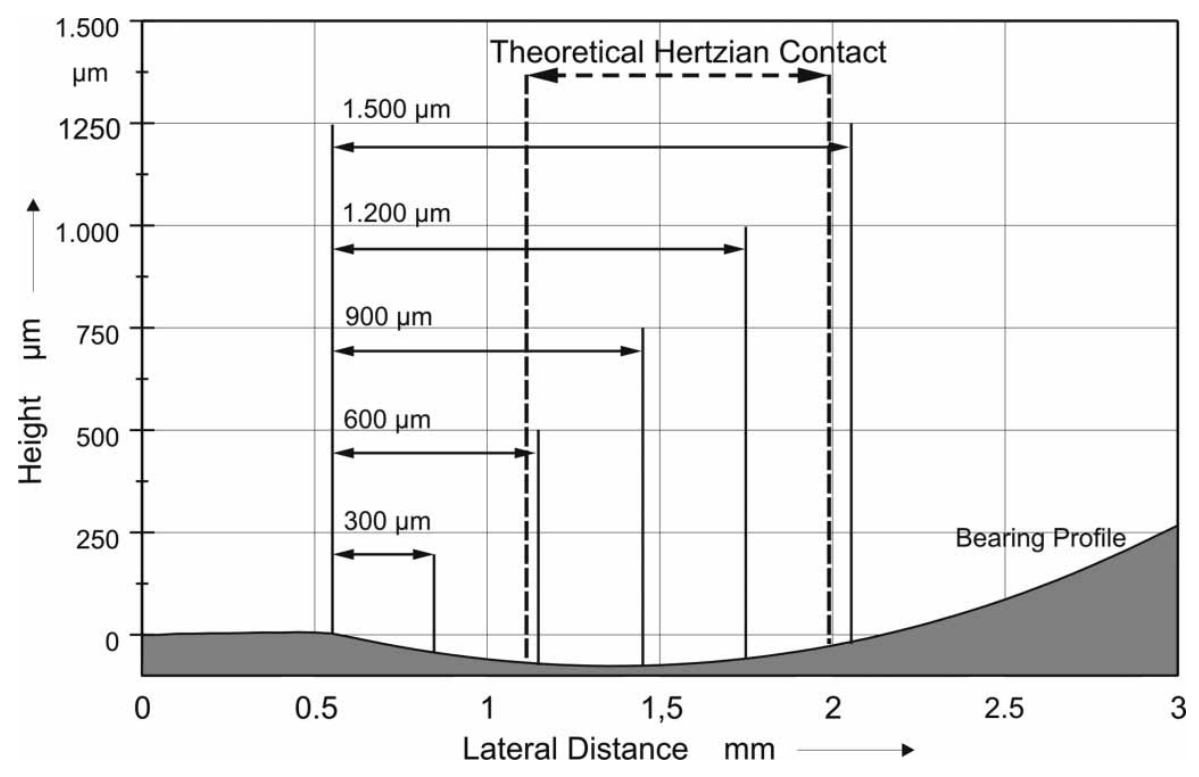

Fig. 12 Bearing profile and the five measurement positions 


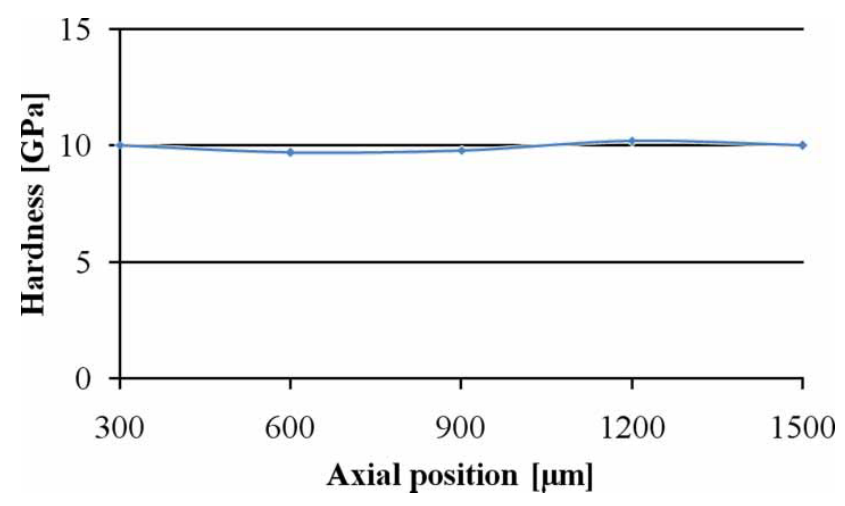

Fig. 13 Hardness on the 'virgin' reference bearing in dependence of the axial position

\section{RESULTS}

\subsection{Operating conditions and service life}

In the following, the main test results are presented. Table 2 gives a comprehensive overview.

The first test runs were performed using Grease I, which is the basic grease without a polymer additive. After a total of four test runs, which adds up to a total of eight tested bearings, of which four failed and four were suspended, the test runs were analysed. The evaluation shows that the average operating temperature on the outer ring of the bearings of Grease I was $69^{\circ} \mathrm{C}$. In total, the grease's service life with 10 per cent failure probability $\left(L_{10}\right)$ was $1010 \mathrm{~h}$ with a slope of 1.7. In all cases, steady operating conditions prevailed after the breaking in phase until approximately $30 \mathrm{~min}$ prior to termination of the test runs. During these final 30 min the bearings' temperature rose rapidly on the outer ring, thus exceeding the maximum tolerable temperature of $100^{\circ} \mathrm{C}$.

After completion of investigations into the plain Grease I, service life tests on greases containing polymers were commenced. Grease II, blended with a non-dispersing PAMA with a low molecular weight, gave a $4{ }^{\circ} \mathrm{C}$ higher average operating temperature than Grease I and an $L_{10}$ of $380 \mathrm{~h}$. Moreover, with a slope $\beta$ of 1.2 of the Weibull distribution, this grease showed a wider spread of results than the grease without polymer.

In direct comparison to Grease II, Grease IV, a nondispersing PAMA, however this time with a higher molecular weight, was studied. In contrast to Grease II, this grease operated at $\sim 2{ }^{\circ} \mathrm{C}$ lower average temperature. Nevertheless, $L_{10}$, which was $140 \mathrm{~h}$, was lower than that for Grease II and $L_{50}$ even much shorter. A possible explanation can be derived by comparing the molecular structure of both polymers. The polymer molecules with a high molecular weight feature longer chains. Therefore, they are sensitive to high shear rates, as is the case in the bearings studied. As previously mentioned, experiments have shown that (a)

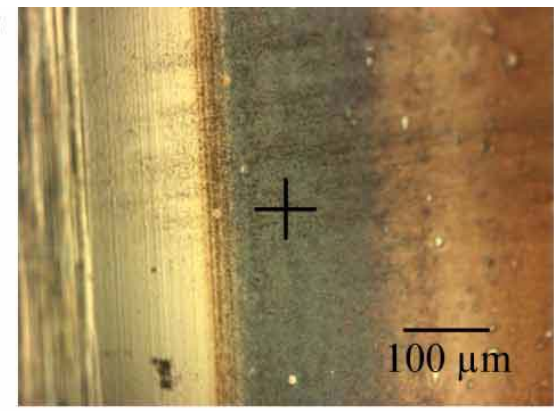

(b)

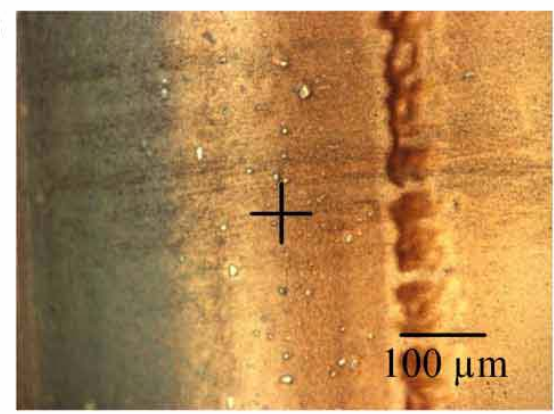

(c)

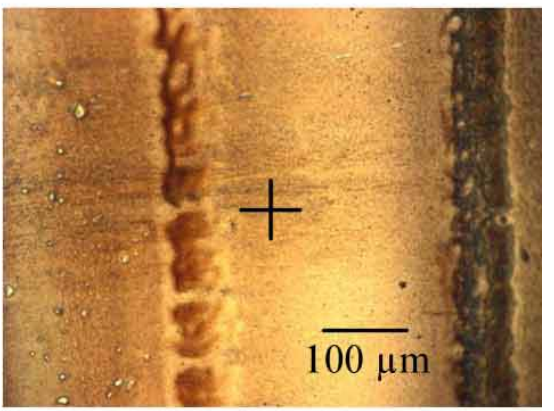

(d)

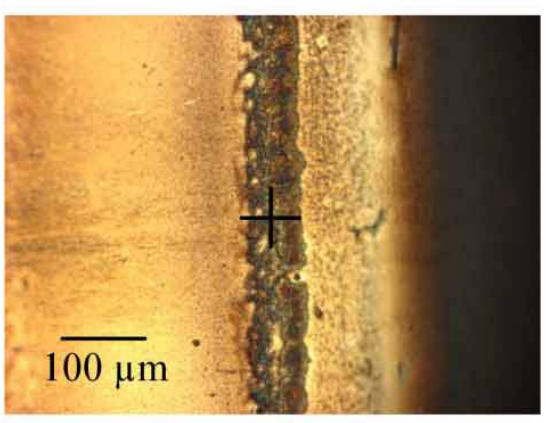

(e)

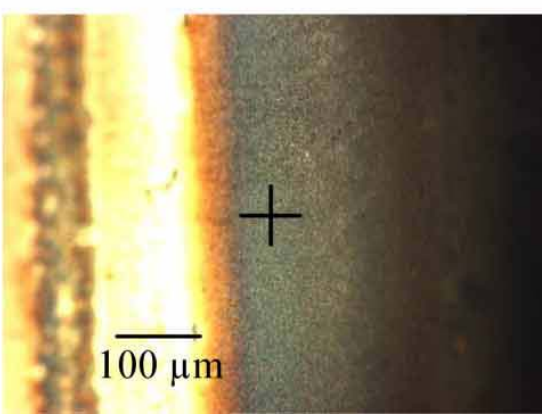

Fig. 14 Photographs of the bearing surface at the positions, at which the indents of Bearing 1 were performed (a) $300 \mu \mathrm{m}$, (b) $600 \mu \mathrm{m}$, (c) $900 \mu \mathrm{m}$, (d) $1200 \mu \mathrm{m}$, and (e) $1500 \mu \mathrm{m}$ 


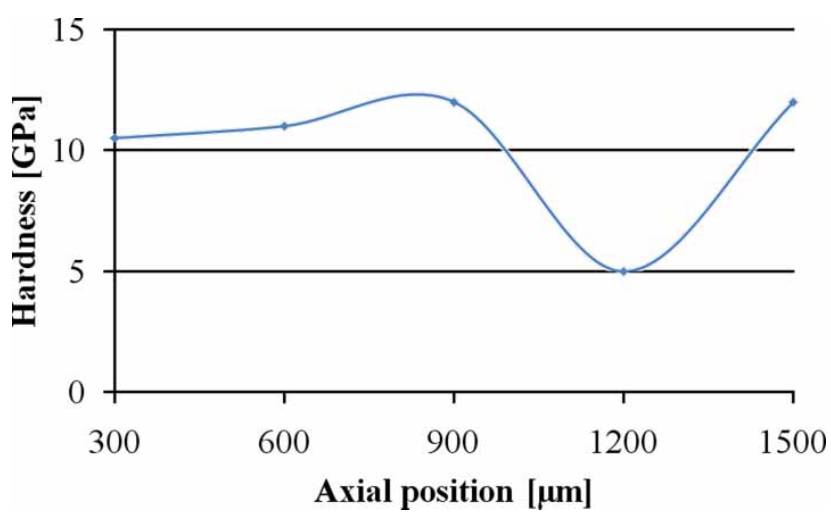

Fig. 15 Hardness versus axial position for Bearing 1

shearing polymers with high molecular weights can lead to a reduction in chain length. Possibly, the longer chains of the polymer in Grease IV are broken into chains shorter than the original ones of grease II.

Figure 7 shows the first $60 \mathrm{~h}$ of the running-in period procedure for Greases I, II, and IV. As the rotating speeds of all three greases increased, the temperatures rose. During the first $10 \mathrm{~h}$ (with rotational speeds up to $10000 \mathrm{r} / \mathrm{min}$ ) Grease IV had the highest temperatures, which were $\sim 10^{\circ} \mathrm{C}$ higher than the temperatures of the plain grease. However, from $30 \mathrm{~h}$ on, when speed rose to $22000 \mathrm{r} / \mathrm{min}$, Grease IV's temperatures started to converge towards the ones of Grease I after two sharp peaks and finally became virtually identical at $26000 \mathrm{r} / \mathrm{min}$. In contrast, Grease II that produced temperatures close to Grease I until $30 \mathrm{~h}$ then started to overtake Grease IV and thereafter consistently gave the highest temperatures of all three greases.

In general, steady conditions were observed for all greases after $\sim 120 \mathrm{~h}$. During a period of $\sim 60 \mathrm{~h}$ after the initial breaking-in phase (not shown in Fig. 7), the temperatures of all examined greases tended to gradually drop $\sim 10^{\circ} \mathrm{C}$.

These observed characteristics can among others be explained as indicated above. While the polymer molecules in Grease II probably kept their original length and therefore produced additional shear resistance, friction, and thus higher temperature at elevated speeds, the longer polymer molecules of Grease IV presumeably ruptured into shorter ones than the ones in Grease II and lost their effect on frictional losses.

Grease III, a dispersing PAMA with a low molecular weight, had an $L_{10}$ value of $427 \mathrm{~h}$, which is the highest of all greases with polymer additives, but at the same time the lowest frictional losses and operating temperatures at full steady-state speed. The runningin period for Grease III in relation to Grease I is depicted in Fig. 8. Although the temperature plots were almost the same for Greases I and III up to rotational speeds of $10000 \mathrm{r} / \mathrm{min}$, the temperature curve of Grease III rose faster than Grease I's when speed (a)

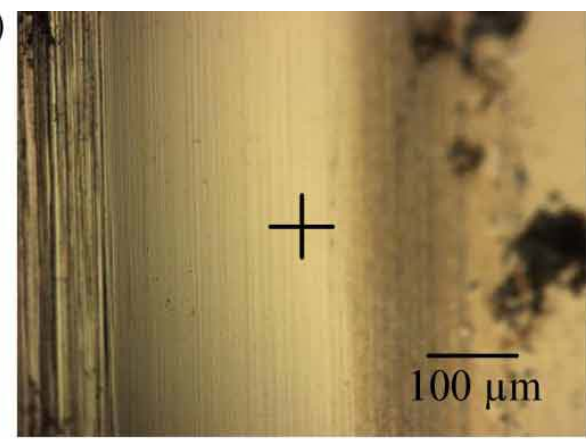

(b))

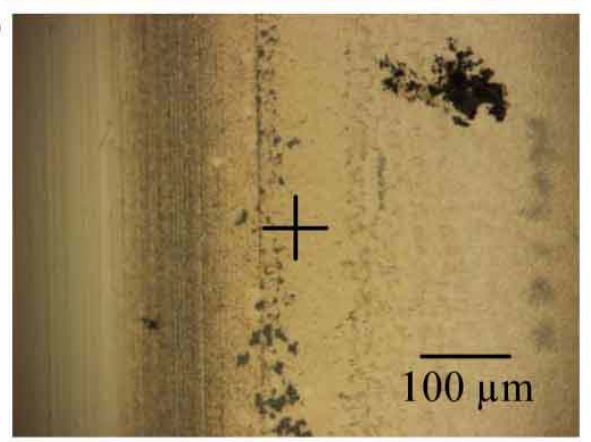

(c)

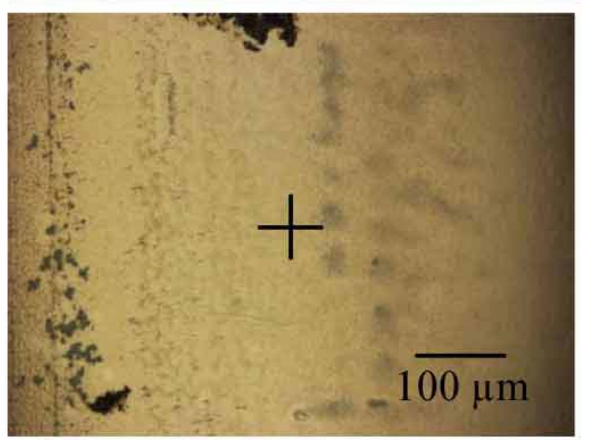

(d)

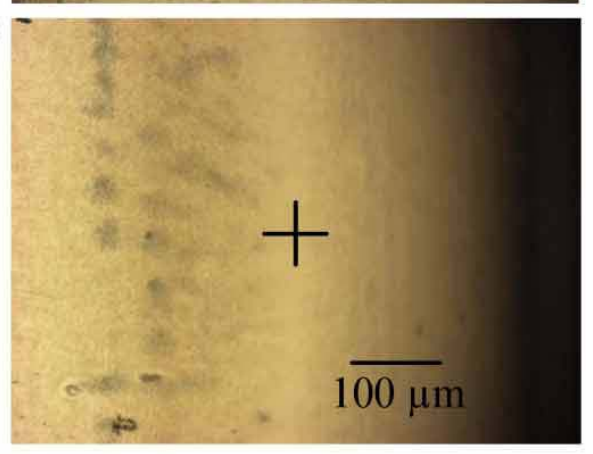

(e)

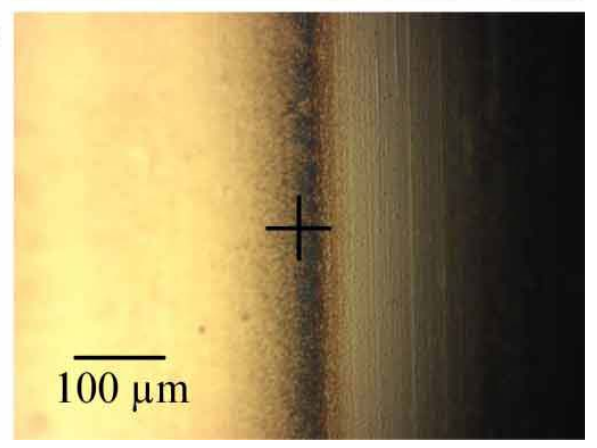

Fig. 16 Photographs of the surfaces of Bearing 2 at the measured positions (a) $300 \mu \mathrm{m}$, (b) $600 \mu \mathrm{m}$, (c) $900 \mu \mathrm{m}$, (d) $1200 \mu \mathrm{m}$, and (e) $1500 \mu \mathrm{m}$ 


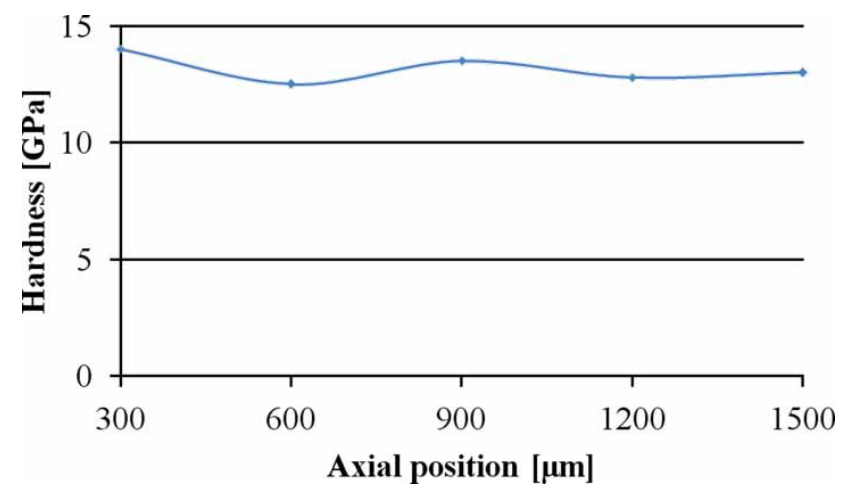

Fig. 17 Hardness versus axial position for Bearing 2

increased to $20000 \mathrm{r} / \mathrm{min}$. However, towards the end of the breaking-in phase, after reaching $26000 \mathrm{r} / \mathrm{min}$, Grease III's temperatures became lower than the ones of Grease I at full speed despite the higher base oil viscosity caused by the polymer.

The final grease to be studied in this test series, Grease V, had an average temperature that was $7{ }^{\circ} \mathrm{C}$ higher than the plain grease. With an $L_{10}$ of $139 \mathrm{~h}$ this grease had the shortest overall service life and the highest operating temperatures. The temperatures were always higher than that for the plain grease during the whole breaking-in period but both trends in principle followed the same pattern.

\subsection{Film thickness measurements}

During the entire course of the investigations film thickness measurements were performed in regular time intervals. Figure 9 shows the relative film thickness values in comparison to the average film thickness measured during the testing of Grease I, which is about $0.1 \mu \mathrm{m}$. The theoretical film thickness of Grease I, determined using the Hamrock Dowson equation for fully flooded point contacts, is $\sim 0.5 \mu \mathrm{m}[13]$. This difference in film thickness can be attributed to starvation.

Greases I, II, and V exhibited only slight difference in film with respect to boundary layer thickness, while the values of grease IV remained about 10 per cent lower. The film or layer thickness of Grease III (the only dispersing PAMA), however, exceeded the other ones by more than a factor of 2 . It should be remembered that bearings lubricated with Grease III operated at the lowest temperature at the same time.

This means that there is no correlation with the nominal base oil viscosity at $40^{\circ} \mathrm{C}$ and ambient pressure, as that one is about the same for all greases with polymers and 45 per cent higher than that for the plain base oil. This confirms the assumption that under the conditions in Hertzian contacts polymers are less effective in enhancing hydrodynamic lubrication than in plain bearings. (a)

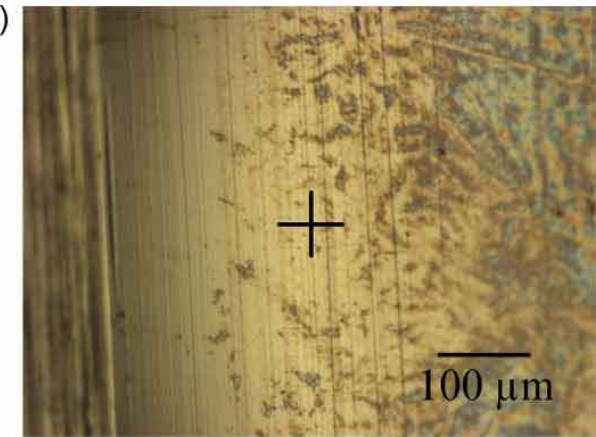

(b)

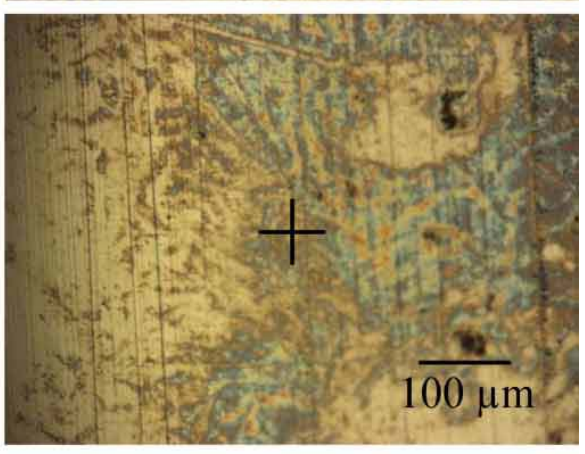

(c)

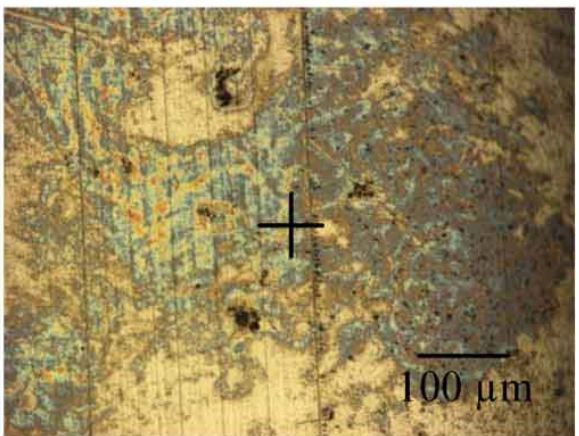

(d)

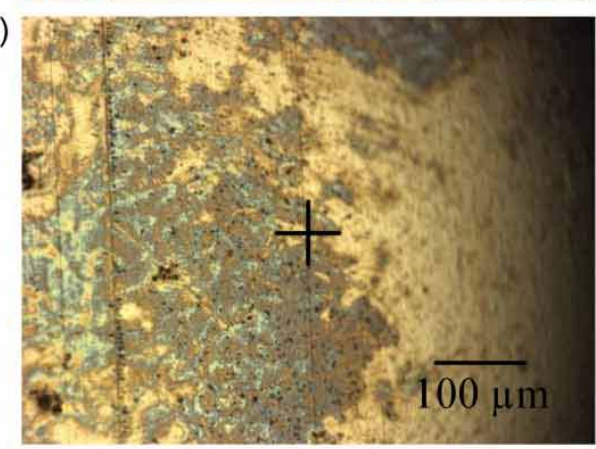

(e)

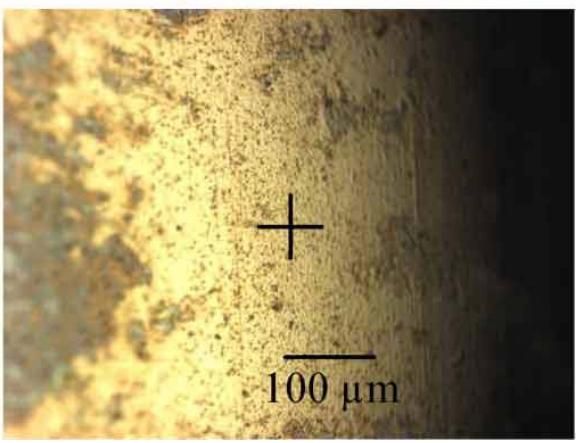

Fig. 18 Photographs of the surfaces of Bearing 3 at the measured positions (a) $300 \mu \mathrm{m}$, (b) $600 \mu \mathrm{m}$, (c) $900 \mu \mathrm{m}$, (d) $1200 \mu \mathrm{m}$, and (e) $1500 \mu \mathrm{m}$ 


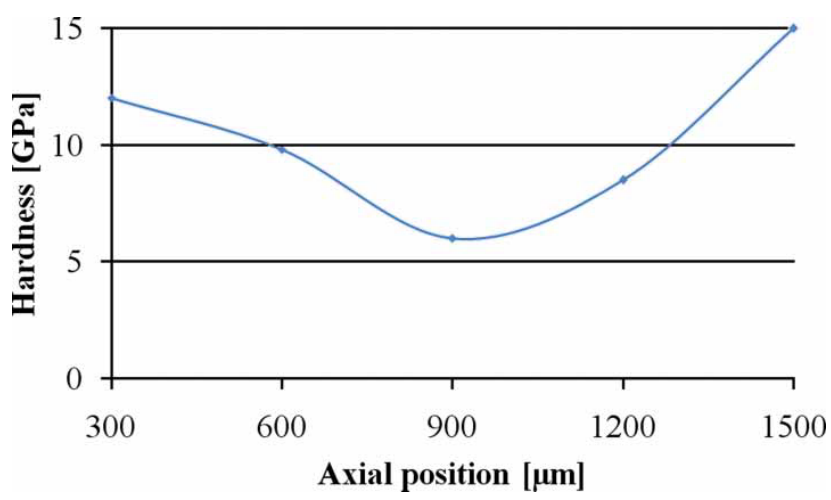

Fig. 19 Hardness versus axial position for Bearing 3

\subsection{Surface hardness measurements by nanoindentation}

As pointed out before, several methods were applied to characterize the physical and mechanical properties of the boundary layers in the contact zone with the aim of establishing a correlation with the different friction characteristics described above. In the following, hardness measurements with a nanoindenter are combined with optical microscopy. All results presented belong to the not failed bearings of the rig tests, which were suspended after failure of the neighbouring one.

\subsubsection{Reference bearing}

As a reference a 'virgin' bearing was measured before the test run. The surface of the bearing shown in Figs 10 and 11 shows an AFM image of an indent on the surface (a) with the corresponding load-displacement curve (b).

When applying a load of $1.5 \mathrm{mN}$, a maximum indentation depth of $90 \mathrm{~nm}$ was recorded with a permanent plastic deformation of $50 \mathrm{~nm}$. The average hardness measured at the five positions on the bearing, which are shown in Fig. 12, was $\sim 10 \mathrm{GPa}$ (Fig. 13). The measurement at $1200 \mu \mathrm{m}$, which is approximately the center of the theoretical Hertzian contact area, showed a hardness slightly exceeding $10 \mathrm{GPa}$. To determine the mean hardness, six indents were performed for each position.

\subsubsection{Bearing 1, Grease I}

On Bearing 1, which was previously run with Grease I, measurements were again taken at the five positions shown in Fig. 12.

The different appearance of the surface depicted in Figs 14 and 15 shows the corresponding hardness values. The hardness values for the bearing surface at positions $300,600,900$, and $1500 \mu \mathrm{m}$ exceeded the values of the reference bearing by about $2 \mathrm{GPa}$. At $1200 \mu \mathrm{m}$, however, close to the centre of the contact path, the measured hardness drops to $5 \mathrm{Gpa}$, half of (a)

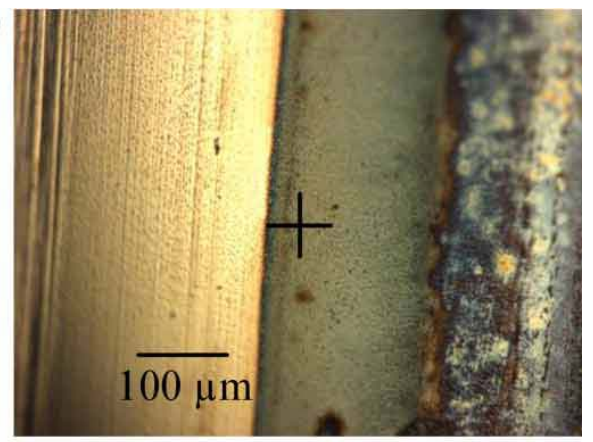

(b)

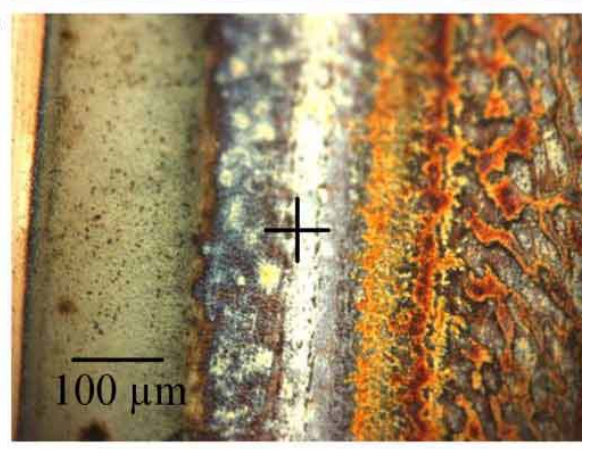

(c)

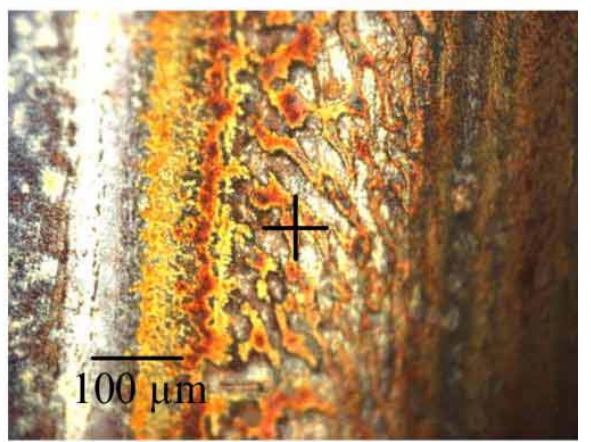

(d)

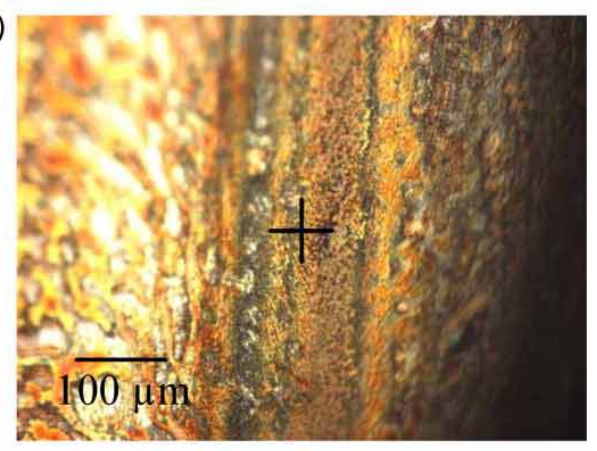

(e)

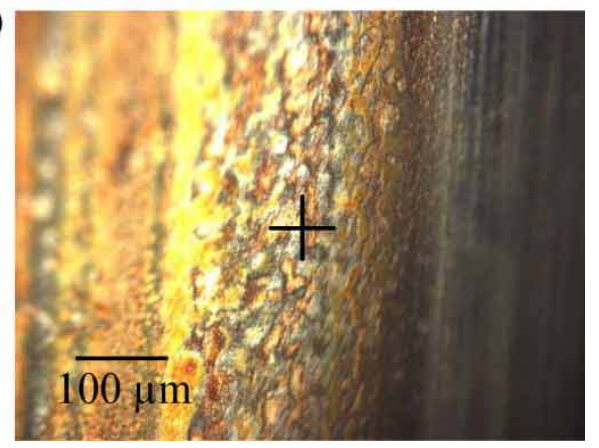

Fig. 20 Photographs of the surfaces of Bearing 4 at the measured positions (a) $300 \mu \mathrm{m}$, (b) $600 \mu \mathrm{m}$, (c) $900 \mu \mathrm{m}$, (d) $1200 \mu \mathrm{m}$, and (e) $1500 \mu \mathrm{m}$ 


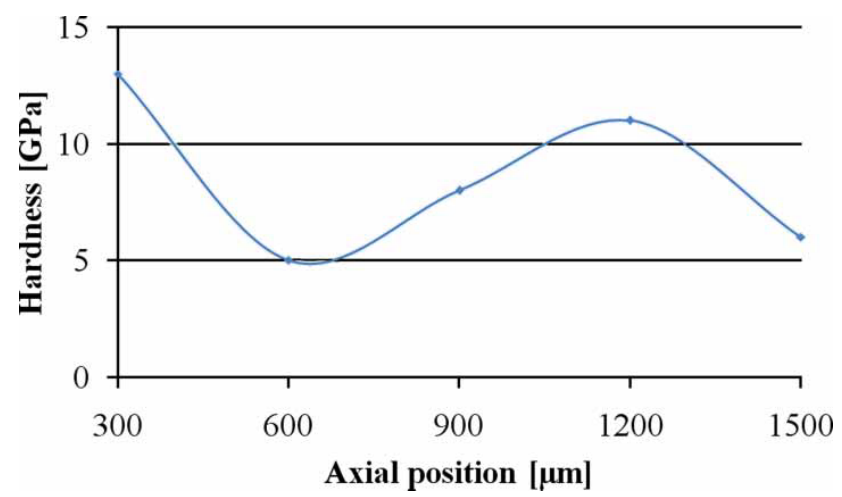

Fig. 21 Hardness versus axial position for Bearing 4

its original value. According to Fig. 14(d), this location happens to feature a narrow circumferential dark trace, possibly a deposit or a reaction layer. As the images depict there is one more of those traces that was incidentally not hit by an indent.

\subsubsection{Bearing 2, Grease II}

Figure 16 depicts the surface of a bearing tested with Grease II. The hardness over the bearing width is nearly constant with values between 12.5 and $14 \mathrm{GPa}$ (Fig. 17) with the lowest value occurring at position $600 \mu \mathrm{m}$ near the border of the contact. There, a circumferential trace with single dark spots is visible in Fig. 16. Again, there are more of those features but they missed being hit by an indent.

\subsubsection{Bearing 3, Grease III}

For the bearing tested with Grease III, the surface shows a grey-blue annealing-like colour nearly over the entire contact path width, as depicted in Fig. 18. In this zone hardness was reduced, with a minimum value of $\sim 6 \mathrm{GPa}$ (Fig. 19) at $900 \mu \mathrm{m}$. On both sides of the discoloured area surface hardness is higher with values of $12 \mathrm{GPa}$ at $300 \mu \mathrm{m}$ and $15 \mathrm{GPa}$ at $1500 \mu \mathrm{m}$.

\subsubsection{Bearing 4, Grease IV}

Bearing 4 tested with Grease IV showed wide circumferential wear tracks. The colours of these tracks are grey, metallic, yellow, and red (Fig. 20).

The wear track at $300 \mu \mathrm{m}$ shows a higher hardness of $13 \mathrm{GPa}$, while the hardness decreases to $5 \mathrm{GPa}$ at $600 \mu \mathrm{m}$ (Fig. 21). At positions of 900 and $1500 \mu \mathrm{m}$ hardness values of 8 and $6 \mathrm{GPa}$, respectively, were measured. At $1200 \mu \mathrm{m}$, there is a zone with a slight increase in hardness to $11 \mathrm{GPa}$.

\subsubsection{Bearing 5, Grease V}

The surface of the Bearing 5 tested with Grease V shows a relatively homogeneous structure (Fig. 22). In the middle of the bearing, there was a region with a (a)

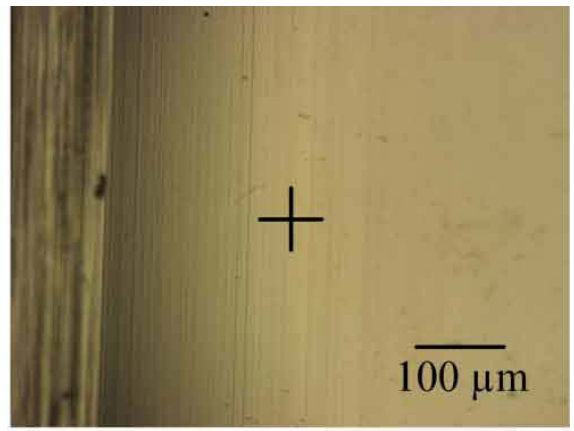

(b)

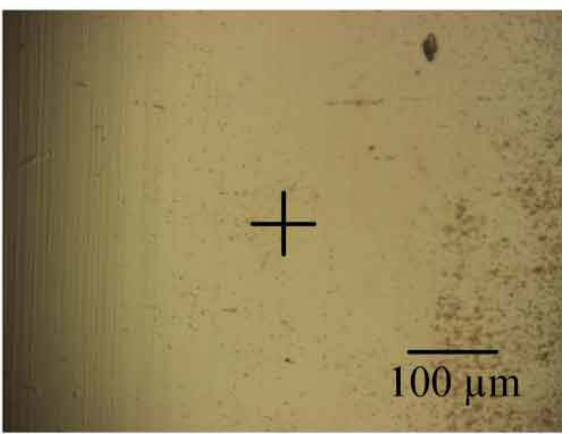

(c)

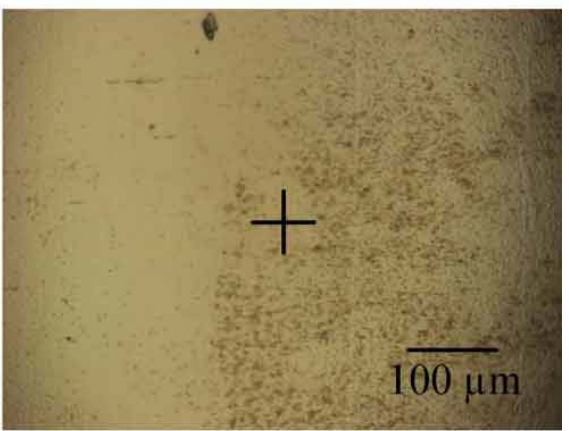

(d)

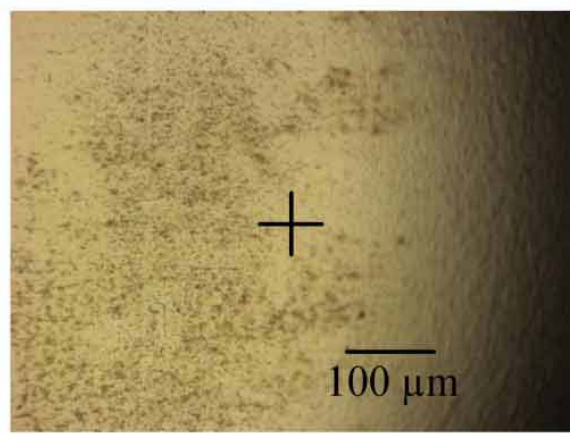

(e)

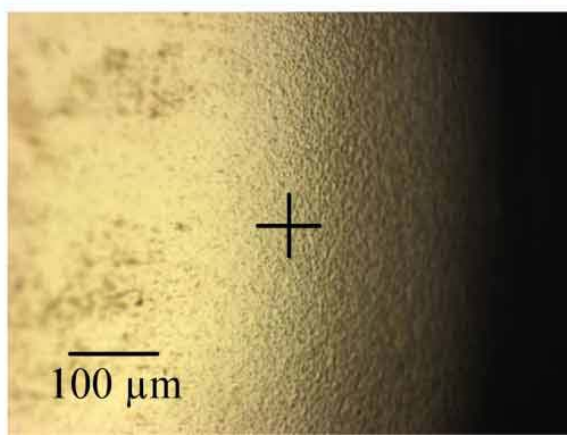

Fig. 22 Photographs of the surfaces of Bearing 5 at the measured positions (a) $300 \mu \mathrm{m}$, (b) $600 \mu \mathrm{m}$, (c) $900 \mu \mathrm{m}$, (d) $1200 \mu \mathrm{m}$, and (e) $1500 \mu \mathrm{m}$ 


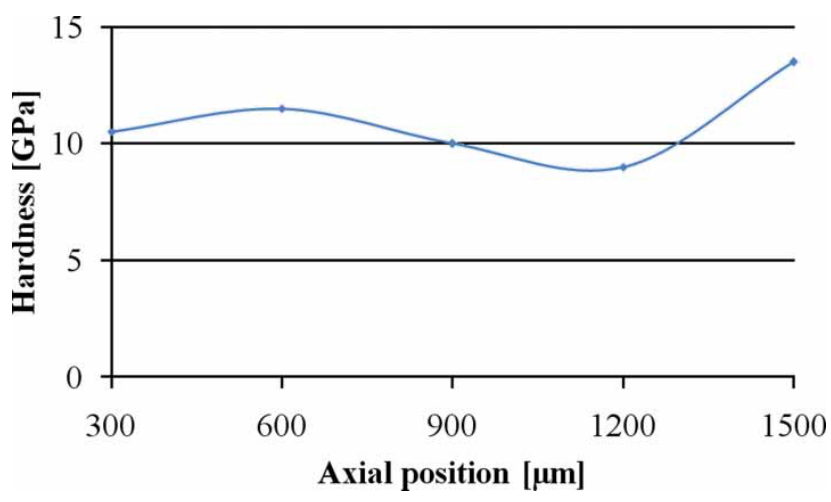

Fig. 23 Hardness versus axial position for Bearing 5

slightly brownish colour at $1500 \mu \mathrm{m}$. At this position the surface was roughened.

The hardness of the bearing surface remained almost constant at $\sim 10 \mathrm{GPa}$. At the position $1500 \mu \mathrm{m}$, the hardness somewhat increased to $13.5 \mathrm{GPa}$, as shown in Fig. 23, and at $120 \mu \mathrm{m}$ it slightly dropped to about $8 \mathrm{GPa}$.

\section{DISCUSSION}

By adding polymer additives to lithium grease the operating characteristics can be influenced. A grease containing a dispersing PAMA with low molecular weight, Grease III, had the longest service life of all blended greases. When comparing the service lives of the plain grease and Grease III, the service life of the plain grease was still longer. Nevertheless, the average temperature of Grease III was the lowest of all examined greases. Furthermore, Grease III built thicker boundary layers. It may be reasoned that the thicker films on the one hand led to a reduction in average temperature, but that on the other hand, Grease III had higher base oil consumption and therefore a shorter service life than Grease I.

A comparison of Greases II and IV showed that the characteristics of the grease blended with long molecules (Grease IV) started to differ from the other greases as the rotational speeds exceeded $10000 \mathrm{r} / \mathrm{min}$. Although this grease had a lower average temperature during the entire testing period, the $L_{10}$ life of Greases IV was also lower. Presumably, the PAMA polymers ruptured, which led to a reduction in chain length and less shear resistance, thereby reducing bearing friction.

Grease V, which was blended with PIB, had the shortest service life and the highest average temperatures of all examined greases. Although film thickness measurements confirmed a slight thickness increase, higher temperatures, which generally indicate higher frictional torque, may explain the short service life.

The macroscopic images of the surfaces show different colours ranging from nearly black to yellow.
Especially, zones with a dark coloured trace or spots showed reduced hardness. Bearings with such features tend to run at lower temperatures. Bearings 1 and 3 (with Greases I and III), which had the lowest average temperatures, also exhibited the greatest reduction in hardness. In contrast, Bearings 2 and 5 (Greases II and $\mathrm{V})$, which ran at higher temperatures, also had the highest hardness.

This indicates that there may be variations in boundary layer formation, which influence friction and can be detected through hardness measurements. At this stage of the investigations, the chemical composition of the differently coloured regions still remains to be studied. Future investigations utilizing secondary ion mass spectroscopy to study the same specimens are expected to allow further insight into the differences in boundary layer composition.

\section{CONCLUSION}

In conclusion, these observations confirm that as expected, polymer additives do indeed influence the operating characteristic and the physical properties of boundary layers of angular contact bearings. In this article five greases, of which four were blended with polymer additives, were studied. It could be shown that the bearing performance varied for nondispersing PAMA, dispersing PAMA, and PIB. It has also been found that dispersing PAMA is particularly effective at creating thick lubricant boundary layers. Furthermore, two similar non-dispersing PAMAs, yet with different chain lengths, were examined. It was observed that varying the chain length of PAMA molecules does influence service life. Furthermore, initially long chains tend to lead to lower average temperatures later on than short chains. Possibly, the long chains transform into shorter ones already during the breaking-in procedure.

Nanoindentation examinations showed variations in surface hardness values for bearings run with blended greases when compared to a virgin bearing. Lower temperatures during rig testing tend to coincide with significant reductions in surface hardness in the contact path. Additional microscopic images of the bearings' surfaces showed important differences in appearance of the boundary layers, which tend to correspond to variations in hardness.

\section{ACKNOWLEDGEMENTS}

The authors wish to thank the German Scientific Association for Mineral Oil, Natural Gas and Coal (DGMK), the German Organisation of Industrial Research Associations (AiF), and the Federal Ministry of Economics and Technology (BMWi) for initiating and supporting this project. 


\section{REFERENCES}

1 Fan, J. Y., Mueller, M., Stoehr, T., and Spikes, H. A. Reduction of friction by functionalised viscosity index improvers. Tribol. Lett., 2007, 28(3), 287-298.

2 Mitsui, H. and Spikes, H. A. Predicting EHD film thickness of lubricant polymer solutions. Tribol. Trans., 1998, 41(1), 1-10.

3 Cann, P. M. and Spikes, H. A. The behaviour of polymer solutions in concentrated contacts: immobile surface layer formation. Tribol. Trans., 1994, 37(3), 580-586.

4 Mueller, M., Topolovec-Miklozic, K., Dardin, A., and Spikes, H. A. The design of boundary film-forming PMA viscosity modifiers. Tribol. Trans., 2006, 49(2), 225-232.

5 Mueller, M., Fan, J. Y., and Spikes, H. A. Design of functionalized PAMA viscosity modifiers to reduce friction and wear in lubricating oils. J. ASTM Int., 2007, 4(10), $1-10$.

6 Kopatsch, F. Systematical investigations of the influence of polymer additives on the EHL-lubricant film thickness. DGMK Report 466, Hamburg, 1999.

7 Bair, S. and Qureshi, F. The high pressure rheology of polymer-oil solutions. Tribol. Int., 2003, 36, 637-645.

8 Franke, J. E. and Poll, G. Service life and lubrication conditions of different grease types in high-speed rolling bearings. In Lubrication at the frontier (Tribology series) (Ed. D. Dowson), vol. 36, 1999, pp. 601-610 (Elsevier, Amsterdam, The Netherlands).

9 Wiendl, S. B., Zabel, W.-R., Gatzen, H. H., and Poll, G. The influence of boundary layer properties on grease lubricated high-speed ball bearing performance. In Proceedings of the 30th Leeds-Lyon Symposium on Tribology, Tribology Series, 2004, vol. 43, pp. 441-447 (Elsevier, Amsterdam, The Netherlands).

10 Pape, F., Yildiz-Ünveren, H. H., Küster, R., Bandorf, R., Bräuer, G., and Gatzen, H. H. Nano-scratch studies on diamond-like carbon coatings on various materials applied in micro actuators. GFT Tribologie-Fachtagung, Göttingen, Germany, vol. 1, 2007, pp. 28/1-28/10.

11 Oliver, W. C. and Pharr, G. M. An improved technique for determining hardness and elastic modulus using load displacement sensing indentation experiments. J. Mater. Res., 1992, 7(6), 1564-1583.

12 Kunert, M. Mechanical properties on nanometer scale and their relations to composition and microstructure. PhD Thesis, Max Planck Society ID No. 200841.0, Universitaet Stuttgart, 2000.

13 Hamrock, B. J. and Dowson, D. A numerical solution to the elastohydrodrodynamic lubrication of point contacts - part III - fully flooded results. Trans. Am. Soc. Mech. Eng., F, 1977, 99(2), 264-275. 